\title{
Evidence for and against regional differences in neural stem and progenitor cells of the CNS
}

\author{
Oren J. Becher ${ }^{1,2}$ and Eric C. Holland $d^{3,4,5,6}$ \\ ${ }^{1}$ Department of Pediatrics, Duke University Medical Center, Durham, North Carolina 27710, USA; ${ }^{2}$ The Preston Robert Tisch \\ Brain Tumor Center, Duke University Medical Center, Durham, North Carolina 27710, USA; ${ }^{3}$ Department of Neurosurgery, \\ Memorial Sloan-Kettering Cancer Center, New York, New York 10021, USA; ${ }^{4}$ Department of Cancer Biology and Genetics, \\ Memorial Sloan-Kettering Cancer Center, New York, New York 10021, USA; ${ }^{5}$ Brain Tumor Center, Memorial Sloan-Kettering \\ Cancer Center, New York, New York 10021, USA
}

Neural stem and progenitor cells (NSCs) give rise to the cellular diversity of the CNS. There is evidence both for and against differences in these cells based on the region of the brain in which they reside. Primary brain tumors mimic many aspects of NSC behavior. Recent data suggest that some of the variability in glioma biology may be, in part, a reflection of regional differences in the NSCs from which they arise. In this issue of Genes \& Development, Lee and colleagues (pp. 2317-2329) examine how NF1 regulates NSC proliferation and glial differentiation in the brainstem and cortex of the postnatal mouse brain.

The CNS develops from a population of neural stem and progenitor cells (NSCs) in a spatially and temporally distinct manner to generate the appropriate types and numbers of neurons and neuroglia of which the mature CNS is comprised. NSCs are defined as cells that can selfrenew and generate all three neural lineages of the CNS: neurons, astrocytes, and oligodendrocytes. One aspect of CNS development that is conserved across all vertebrates is its order: Prenatal neurogenesis precedes postnatal gliogenesis. Neurogenesis has been studied extensively, while gliogenesis has been largely unexamined. The development of the mammalian cerebral cortex serves as a wellcharacterized example of neurogenesis. The earliest progenitor cells constitute a single layer of neuroepithelial cells, which express both Sox1 and RC2. These neuroepithelial cells give rise to elongated radial glia cells that extend from the ventricle to the pia, and thus span the thickness of the cortical wall. Radial glia are thought to give rise to all of the neurons of the cortex. Radial glia are diverse: The majority express Pax6, RC2, and nestin, while

[Keywords: Neurofibromin; neural stem cell; regional heterogeneity; gliogenesis; Akt; mTOR

${ }^{6}$ Corresponding author.

E-MAIL hollande@mskcc.org; FAX (646) 422-0231.

Article is online at http://www.genesdev.org/cgi/doi/10.1101/gad.1988010. subsets of radial glia cells express the brain lipid-binding protein (BLBP) and the glutamate aspartate transporter (GLAST). The radial glia produce a second germinal zone-the subventricular zone (SVZ)-where transitamplifying cells are generated to create the neuronal and glial populations. Radial glia eventually give rise to astrocytes, when they lose their apical foot and translocate toward the pia (Okano and Temple 2009).

Once the mature CNS is formed shortly after birth, there is little in vivo evidence for neurogenesis continuing into adulthood, with the exception of the SVZ of the lateral ventricles and the subgranular zone of the hippocampus. In contrast, brainstem development is less well understood, although the contribution of the rhombic lip-an embryonic proliferative epithelium located on the dorsal aspect of the fourth ventricle-to brainstem nuclei (such as the inferior olive nucleus) and mossy or climbing fiber nuclei has been addressed (Landsberg et al. 2005).

Neurofibromatosis type 1 (NF1) is a common autosomal dominant disorder in which affected individuals develop abnormalities involving both astrocytes and neurons. Not only are children and adults with NF1 at high risk for developing low-grade astrocytic tumors, but $40 \%-60 \%$ of children with NF1 also exhibit specific learning disabilities that are associated with low IQ scores. The NF1 gene encodes a large cytoplastic protein, neurofibromin, which primarily functions as a negative regulator of the Ras proto-oncogene. Loss or reduced neurofibromin expression results in increased Ras activity due to the absent or decreased function of neurofibromin's GTPase-activating protein (GAP) (Hegedus et al. 2007).

Mouse models of NF1 have been instrumental in unraveling the complicated biology of neurofibromatosis. While biallelic NF1 inactivation is observed in NF-1-associated gliomas, astrocyte-restricted NF1 conditional knockout mice do not develop gliomas (GFAP-cre; $N F 1^{\mathrm{fl} / \mathrm{fl}}$ ). Interestingly, loss of NF1 in astrocytes from $N F 1^{+/-}$mice using the same cre mouse line-which more accurately recapitulates the biology of the human disease-does result in the 


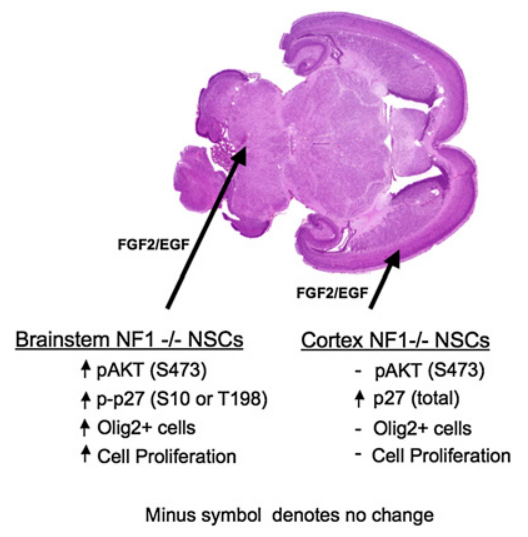

Figure 1. Region-specific NSCs from a PN1 mouse brain. Horizontal low-magnification H\&E staining from a PN1 mouse brain. The large arrow points to the brainstem and the small arrow points to the cortex. NF1 ${ }^{-/-}$NSCs isolated from a PN1 brainstem and cultured in serum-free conditions with FGF-2/ EGF had increased pAKT (S473), increased p-p27 (S10 and T198), increased Olig-2-expressing cells, and increased proliferation rate relative to $\mathrm{NF}^{+/+}$NSCs isolated from a PN1 brainstem. In contrast, $N F 1^{-1-}$ NSCs isolated from a PN1 cortex had similar levels of pAKT (S473), increased total p27 protein levels, similar number of Olig-2-expressing cells, and similar proliferation rate relative to $\mathrm{NF}^{+/+}$NSCs isolated from a PN1 cortex. (Image courtesy of Massimo Squatrito.)

formation of optic gliomas (Bajenaru et al. 2003). It is worth noting that a second mouse model was developed using a different GFAP promoter, hGFAP-cre; $N F 1^{\mathrm{fl} / \mathrm{fl}}$, which also develops optic gliomas. The discrepancy in phenotype between the mouse models may be due to differential timing of cre transgene activation, as the latter is activated earlier in development (Zhu et al. 2005). As neurofibromatosis affects both the neuronal and glial lineages, the role of NF1 in embryonic telencephalic NSCs from embryonic day 10.5 (E10.5) mice includes a role in NSC proliferation, survival, and astroglial differentiation (Dasgupta and Gutmann 2005). Of note, a third mouse model of optic glioma generated using a BLBP-cre; $N F 1^{\mathrm{fl} / \mathrm{fl}}$ mouse line has provided strong evidence for a Ras-independent function of NF1 in the regulation of normal neuronal differentiation and forebrain cortical development through the positive regulation of cyclic AMP (cAMP) levels (Hegedus et al. 2007).

The neurosphere assay is an in vitro assay where cells are cultured in serum-free conditions in the presence of high doses of epidermal growth factor (EGF) and fibroblast growth factor 2 (FGF2). This assay can be used to assess for proliferation, self-renewal, and capacity for multilineage differentiation of neural progenitors into astrocytes, neurons, and oligodendrocytes. Using this assay, it was shown that multipotent CNS stem cells are present in the adult mammalian spinal cord, as well as throughout the ventricular neuroaxis. It was further demonstrated that these different regions harbor varying numbers of multipotent CNS stem cells, with the lateral ventricle and lumbar/sacral spinal cord having the greatest number, and the fourth ventricle having the least
(Weiss et al. 1996). The notion of the temporal regulation of NSCs was further supported by the observation that E11.5 cortex-derived NSCs persistently self-renew and are more neurogenic and proliferative, while postnatal day 0 (PNO) cortex-derived NSCs are more restricted, less neurogenic, and less proliferative (Shoemaker et al. 2010). There have been numerous studies evaluating intrinsic and extrinsic factors regulating embryonic and adult NSCs, including FGF2, EGF, and insulin-like growth factor 1, all of which can increase the size of the NSC pool (Reynolds et al. 1992; Arsenijevic et al. 2001). Examples of cell-intrinsic molecules include the notch effector Hes-1, PTEN, Bmi-1, and Akt-1 (Nakamura et al. 2000; Sinor and Lillien 2004; Molofsky et al. 2005; Groszer et al. 2006).

\section{Evidence for regional differences in NSCs during development}

There has been recent interest in addressing whether NSCs from diverse regions of the CNS harbor intrinsic region-specific differences. This question has been studied in both rodents and human tissues by several laboratories, partly to address the potential for human neural progenitors from different regions of the CNS to serve as candidate cells for cell transplantation therapy for neurodegenerative disorders. Numerous studies demonstrate that rodent and human neurospheres derived from embryonic or adult CNS tissue retain regional specification, as assessed by proliferation or differentiation experiments and the expression of region-specific markers /Ostenfeld et al. 2002; Horiguchi et al. 2004; Fu et al. 2005; Kelly et al. 2009). A related question is whether these regionally specified NSC lineages are plastic and responsive to external cues or are irreversible. Coculture experiments of slice cultures derived from the anterior part of the brain (ventral forebrain) can induce neurospheres derived from further back in the brain structure (midbrain/hindbrain) to express ventral forebrain-specific markers (Hitoshi et al. 2002) in mice and even across species (Kim et al. 2006). Moreover, spinal cord neural progenitors that are transplanted into the neonatal forebrain SVZ maintain intrinsic properties (such as expressing spinal cord neuron-specific enzymes), respond to extrinsic cues, migrate extensively, integrate into the host brain, and differentiate (Yang et al. 2000).

To address why brain tumors in children arise in specific locations, Gutmann and colleagues (Yeh et al. 2009) previously performed expression profiling at PN1 on primary astrocyte cultures from several brain locations, including the optic nerve, cerebellum, brainstem, and cortex. They observed that NF1 mRNA and protein levels were decreased in neocortical astrocytes relative to astrocytes that arise in other parts of the brain. Loss of NF1 in astrocytes in vivo and in vitro has differential results, depending on the region-specific location. Loss of NF1 in cerebellar, brainstem, and optic nerve astrocytes resulted in increased proliferation, while loss of NF1 in cortical astrocytes does not affect proliferation (Yeh et al. 2009). A second hypothesis suggests that lower levels of cAMP may provide a more permissive microenvironment 
for NF1-associated gliomagenesis, as areas such as the brainstem, cerebellum, and optic nerve-where NF1associated gliomas are more common-have lower cAMP levels relative to the cortex (Warrington et al. 2007).

\section{Evidence against regional differences in NSCs during development}

One major concern with the in vitro neurosphere assay is the potential for dedifferentiation or other genetic modifications of the cells due to extended exposure to mitogens such as FGF2 (Gage 2000). The validity of the assay has been challenged through the demonstration that the clonogenic competence to generate neurons, astrocytes, and oligodendrocytes in the spinal cord is due to deregulation of dorsoventral patterning during expansion in vitro (Gabay et al. 2003). In addition, others observed prominent down-regulation of most transcription factors present in telencephalic precursors from the anterior part of the brain upon growth factor exposure in neurosphere cultures, while Olig1 and Olig2 expression was strongly up-regulated (Hack et al. 2004). A third group (Santa-Olalla et al. 2003) observed that neither anteroposterior (AP) nor dorsoventral (DV) cell position identity is preserved in NSCs grown in culture. More recently, in vitro observations regarding the importance of Bmi-1 in NSC self-renewal and proliferation were not observed in vivo, suggesting that in vitro observations should be interpreted with caution (He et al. 2009).

In this issue of Genes \& Development, Gutmann and colleagues (Lee et al. 2010) continue their investigations into brain region-specific effects due to NF1 loss in NSCs from the postnatal brainstem and cortex. Surprisingly, loss of NF1 in NSCs derived from the brainstem at PN1 results in increased NSC proliferation and gliogenesis, but loss of NF1 in NSCs derived from the neocortex at the same postnatal day does not. Although Lee et al. (2010) use in vitro NSC cultures to demonstrate the brain region-specific differences due to NF1 loss, they confirm their in vitro results with in vivo observations using BLBP-cre; $N F 1^{\mathrm{fl} / \mathrm{fl}}$ mice, which correlate closely in this work. Furthermore, Lee et al. (2010) note that loss of NF1 in brainstem NSCs resulted in an increase in the number of Olig2-expressing cells both in vitro and in vivo. Next, they investigated the molecular mechanism for this differential response to NF1 loss in NSCs, and observed selective Akt activation in the brainstem NSCs, which does not occur in cortex NSCs due to increased rictor expression in the brainstem and not in the cortex. Finally, Lee et al. (2010) observed that this brainstem-specific Akt activation results in decreased expression of p27 in the brainstem and not in the cortex. Thus, the molecular mechanism for increased NSC proliferation and gliogenesis in the brainstem appears to be initiated by TORC2. It is unclear why NF1 loss specifically in brainstem NSCs results in TORC2 up-regulation.

It is worth noting that Lee et al. (2010) also demonstrate that this differential response of NSCs to NF1 loss between the brainstem and cortex was present during embryonic development at E13.5. However, Dasgupta and Gutmann (2005) demonstrated previously that loss of NF1 in the telencephalon (the embryonic structure from which the cerebral cortex develops) at E10.5 results in increased proliferation in NSCs, and loss of NF1 in BLBP-Cre; NF1 ${ }^{\mathrm{fl} / \mathrm{fl}}$ (which recombines at E9.5) results in increased Olig2 ${ }^{+}$ progenitors and increased gliogenesis in the hippocampus postnatally at PN8 (Hegedus et al. 2007). Together with the current observation by Lee et al. (2010) of modestly increased proliferation and gliogenesis associated with the loss of NF1 in the postnatal SVZ in vitro and in vivo, these observations suggest an alternative possible interpretation: Gliogenesis takes place at different regions of the CNS at distinct time points, with more caudal structures completing gliogenesis at later time points. This explanation has been suggested with regards to radial glia and neurogenesis (Anthony et al. 2004).

A second mouse line was generated where the cre recombinase is driven by the human GFAP promoter (hGFAPcre; $N F 1^{\mathrm{fl} / \mathrm{fl})}$ and undergoes recombination at E10.5. This results in increased glial progenitors that express nestin and BLBP throughout the brain at PN8, as well as increased GFAP-positive astrocytes in both white and gray matter, including corpus callosum and anterior commissure (Zhu et al. 2005). However, it is important to note that there are several technical aspects of mouse modeling that can generate apparent discrepancies in cell type identification. Transgene promoters do not reflect the true expression of a gene with $100 \%$ accuracy due to integration site effects and regulatory elements that are not included in the transgene. In addition, the expression of cre recombinase may be leaky, and different genetic backgrounds of the mice may influence transgene expression.

Akt activation has been shown to regulate the proliferation of NSCs through a variety of mechanisms. First, PTEN, a negative regulator of Akt, regulates the stem cell self-renewing state of normal NSCs (Groszer et al. 2006). A second mechanism involves CXCL12 (also called stromal cell-derived factor 1 [SDF-1]), which binds CXCR4 and activates Akt1. This binding results in the phosphorylation of FOXO3a, a negative regulator of cell cycle progression (Wu et al. 2009). The third mechanism is the one described here, where Akt is activated through TORC2. Interestingly, the cyclin-dependent kinase inhibitor p27 has been implicated previously in NSC biology as a cell cycle inhibitor that regulates the transit-amplifying cells or type C cells in the SVZ of the lateral ventricle of adult mice (Doetsch et al. 2002). Consequently, adult p27-null mice have increased glial cells in the hippocampus and cerebellum (Casaccia-Bonnefil et al. 1997). Based on these data, one would hypothesize that p27-null mice may display increased postnatal gliogenesis in the brainstem, but not in the cortex.

\section{Evidence for brain region-specific differences in brain tumors}

Brain tumors are thought to arise through the acquisition of genetic alterations in NSCs (Huse and Holland 2010). These results suggest that histologically similar brain 
tumors that arise in different brain regions may harbor region-specific signaling that may be related to regionspecific NSCs. Pilocytic astrocytomas (PAs) are low-grade pediatric gliomas that do not transform into high-grade tumors and are especially frequent in children with NF1. A comparison of expression profiles of supratentorial and posterior fossa PAs demonstrated molecular differences whereby 28 genes were overexpressed in supratentorial PAs, and only eight genes were overexpressed in posterior fossa PAs. Most of these genes were developmentally regulated, such as paired box gene 3 (PAX3), which was overexpressed in posterior fossa PAs, and LIM homeobox 2 (LHX2), which was overexpressed in supratentorial PAs. While the simplest interpretation would be that these patterns are due to normal contaminating cells in the respective tumors, these molecular differences were also present in astrocytes and NSCs cultured from these regions, suggesting that PAs from different regions of the CNS are biologically distinct (Sharma et al. 2007).

Ependymomas are perhaps the most compelling examples of histologically similar tumors, having region-specific molecular alterations as well as distinct putative cells of origin. In fact, ependymoma is one of the few CNS tumor types where location and age independently significantly influence survival, with spinal tumors having the best overall prognosis (McGuire et al. 2009). The molecular signature of ependymomas differs depending on the location of the tumor in the CNS: spinal, posterior fossa, and supratentorial. It was noted that ependymomas, as well as ependymoma NSCs from each region, harbored gene expression profiles that corresponded to the respective regionally specified radial glia progenitor cells. Furthermore, ependymomas from different parts of the CNS display distinct patterns of copy number-driven gene expression. For example, Ink4a-ARF loss is seen primarily in supratentorial - rather than spinal-ependymomas. Thus, the likely cells of origin for this tumor are the radial glia cells, which maintain unique signatures depending on their location (Taylor et al. 2005).

High-grade gliomas (HGGs) in children most commonly arise in the cortex or the brainstem. A recent study used SNP arrays to compare the copy number alterations (CNA) of gliomas arising in the brainstem and those arising in the cortex. Zarghooni et al. (2010) reported that the CNAs were different between the brainstem tumors and their supratentorial counterparts: Supratentorial HGGs showed more frequent loss of $9 \mathrm{p}$ and $4 \mathrm{q}$, while brainstem HGGs showed more frequent loss of 11p, 17p, 14q, 18p, and 22q. However, a separate report did not observe any statistically significant differences between supratentorial and brainstem HGGs with regards to gains or losses of all individual chromosome arms, PDGFRA amplification, or CDKN2a deletion (Paugh et al. 2010). More detailed differences in larger samples of brainstem and supratentorial HGGs remain to be described, and will likely unravel significant differences with regards to the genomic alterations and molecular signatures that brainstem and cortical gliomas have.

The findings reported by Gutmann and colleagues (Lee et al. 2010) describing brain region-specific regulation of
NSCs by NF1 add to the increasing body of evidence in support of regional and temporal regulation of NSCs. One significant observation is that postnatal gliogenesis in the brainstem is regulated by Akt activation. Postnatal gliogenesis in the neonatal SVZ arises from several progenitor pools: radial glia, distal-less homeobox 2 (DLX-2)-expressing progenitors, and NG2 ${ }^{+}$cells (Hewett 2009). As all of these progenitors may express Olig-2, it is not clear which population of progenitors is active in the brainstem and where they arise from during development. While the location of postnatal stem cells in the adult cortex is known, and postnatal cerebellar stem cells are thought to reside in the white matter (Lee et al. 2005), there is limited data as to where neural stem cells reside in the adult brainstem. In vitro, the NSCs described by Gutmann and colleagues (Lee et al. 2010) express both nestin and BLBP, both known markers of NSCs and radial glia. Recently, a brainstem glioma mouse model was developed through overexpression of PDGF-B, where it was observed that nestin-expressing cells of the floor of the fourth ventricle at PN1-3 may serve as cells of origin (Becher et al. 2010). However, a brainstem glioma rat model, which overexpresses PDGF-B via retroviral vectors at $\mathrm{PN} 3$, suggests that NG2-expressing cells, located throughout the brainstem, may also serve as cells of origin (Masui et al. 2010).

Given that it is likely that cells of origin for gliomas are NSCs from the region of origin, together with the assumption that these murine brain region-specific observations are conserved from mice to humans, the results reported by Gutmann and colleagues (Lee et al. 2010) suggest that gliomas that arise in the brainstem may be sensitive to mTOR blockade. NF1 is now known to undergo biallelic inactivation not only in PAs that arise in children with NF1, but also in a subset of adult HGGs (Cancer Genome Atlas Research Network 2008) and pediatric HGGs (Paugh et al. 2010). Another potential mechanism for loss of NF1 in gliomagenesis is degradation of NF1 via the ubiquitinproteasome pathway (McGillicuddy et al. 2009). It remains to be determined whether inhibition of AKT signaling will be a more successful strategy against glial tumors that arise in the brainstem, as opposed to those that arise in the cortex.

\section{References}

Anthony TE, Klein C, Fishell G, Heintz N. 2004. Radial glia serve as neuronal progenitors in all regions of the central nervous system. Neuron 41: 881-890.

Arsenijevic Y, Weiss S, Schneider B, Aebischer P. 2001. Insulinlike growth factor-I is necessary for neural stem cell proliferation and demonstrates distinct actions of epidermal growth factor and fibroblast growth factor-2. I Neurosci 21: 7194-7202.

Bajenaru ML, Hernandez MR, Perry A, Zhu Y, Parada LF, Garbow JR, Gutmann DH. 2003. Optic nerve glioma in mice requires astrocyte $\mathrm{Nf1}$ gene inactivation and $\mathrm{Nf1}$ brain heterozygosity. Cancer Res 63: 8573-8577.

Becher OJ, Hambardzumyan D, Walker TR, Helmy K, Nazarian J, Albrecht S, Hiner RL, Gall S, Huse JT, Jabado N, et al. 2010. Preclinical evaluation of radiation and perifosine in a genetically and histologically accurate model of brainstem glioma. Cancer Res 70: 2548-2557. 
Cancer Genome Atlas Research Network. 2008. Comprehensive genomic characterization defines human glioblastoma genes and core pathways. Nature 455: 1061-1068.

Casaccia-Bonnefil P, Tikoo R, Kiyokawa H, Friedrich V Jr, Chao MV, Koff A. 1997. Oligodendrocyte precursor differentiation is perturbed in the absence of the cyclin-dependent kinase inhibitor p27Kip1. Genes Dev 11: 2335-2346.

Dasgupta B, Gutmann DH. 2005. Neurofibromin regulates neural stem cell proliferation, survival, and astroglial differentiation in vitro and in vivo. J Neurosci 25: 5584-5594.

Doetsch F, Verdugo JM, Caille I, Alvarez-Buylla A, Chao MV, Casaccia-Bonnefil P. 2002. Lack of the cell-cycle inhibitor p27Kip1 results in selective increase of transit-amplifying cells for adult neurogenesis. I Neurosci 22: 2255-2264.

Fu SL, Ma ZW, Yin L, Iannotti C, Lu PH, Xu XM. 2005. Regionspecific growth properties and trophic requirements of brainand spinal cord-derived rat embryonic neural precursor cells. Neuroscience 135: 851-862.

Gabay L, Lowell S, Rubin LL, Anderson DJ. 2003. Deregulation of dorsoventral patterning by FGF confers trilineage differentiation capacity on CNS stem cells in vitro. Neuron 40: $485-499$.

Gage FH. 2000. Mammalian neural stem cells. Science 287: 1433-1438.

Groszer M, Erickson R, Scripture-Adams DD, Dougherty JD, Le Belle J, Zack JA, Geschwind DH, Liu X, Kornblum HI, Wu H. 2006. PTEN negatively regulates neural stem cell selfrenewal by modulating G0-G1 cell cycle entry. Proc Natl Acad Sci 103: 111-116.

Hack MA, Sugimori M, Lundberg C, Nakafuku M, Gotz M. 2004. Regionalization and fate specification in neurospheres: The role of Olig2 and Pax6. Mol Cell Neurosci 25: 664-678.

He S, Iwashita T, Buchstaller J, Molofsky AV, Thomas D, Morrison SJ. 2009. Bmi-1 over-expression in neural stem/ progenitor cells increases proliferation and neurogenesis in culture but has little effect on these functions in vivo. Dev Biol 328: 257-272.

Hegedus B, Dasgupta B, Shin JE, Emnett RJ, Hart-Mahon EK, Elghazi L, Bernal-Mizrachi E, Gutmann DH. 2007. Neurofibromatosis-1 regulates neuronal and glial cell differentiation from neuroglial progenitors in vivo by both cAMP- and Ras-dependent mechanisms. Cell Stem Cell 1: 443-457.

Hewett JA. 2009. Determinants of regional and local diversity within the astroglial lineage of the normal central nervous system. I Neurochem 110: 1717-1736.

Hitoshi S, Tropepe V, Ekker M, van der Kooy D. 2002. Neural stem cell lineages are regionally specified, but not committed, within distinct compartments of the developing brain. Development 129: 233-244.

Horiguchi S, Takahashi J, Kishi Y, Morizane A, Okamoto Y, Koyanagi M, Tsuji M, Tashiro K, Honjo T, Fujii S, et al. 2004. Neural precursor cells derived from human embryonic brain retain regional specificity. J Neurosci Res 75: 817-824.

Huse JT, Holland EC. 2010. Targeting brain cancer: Advances in the molecular pathology of malignant glioma and medulloblastoma. Nat Rev Cancer 10: 319-331.

Kelly TK, Karsten SL, Geschwind DH, Kornblum HI. 2009. Cell lineage and regional identity of cultured spinal cord neural stem cells and comparison to brain-derived neural stem cells. PLOS ONE 4: e4213. doi: 10.1371/journal.pone.0004213.

Kim HT, Kim IS, Lee IS, Lee JP, Snyder EY, Park KI. 2006. Human neurospheres derived from the fetal central nervous system are regionally and temporally specified but are not committed. Exp Neurol 199: 222-235.

Landsberg RL, Awatramani RB, Hunter NL, Farago AF, DiPietrantonio HJ, Rodriguez CI, Dymecki SM. 2005. Hind- brain rhombic lip is comprised of discrete progenitor cell populations allocated by Pax6. Neuron 48: 933-947.

Lee A, Kessler JD, Read TA, Kaiser C, Corbeil D, Huttner WB, Johnson JE, Wechsler-Reya RJ. 2005. Isolation of neural stem cells from the postnatal cerebellum. Nat Neurosci 8: 723-729.

Lee DY, Yeh TH, Emnett RJ, White CR, Gutmann DH 2010. Neurofibromatosis-1 regulates neuroglial progenitor proliferation and glial differentiation in a brain region-specific manner. Genes Dev (this issue). doi: 10.1101/gad.1957110.

Masui K, Suzuki SO, Torisu R, Goldman JE, Canoll P, Iwaki T. 2010. Glial progenitors in the brainstem give rise to malignant gliomas by platelet-derived growth factor stimulation. Glia 58: 1050-1065.

McGillicuddy LT, Fromm JA, Hollstein PE, Kubek S, Beroukhim R, De Raedt T, Johnson BW, Williams SM, Nghiemphu P, Liau LM, et al. 2009. Proteasomal and genetic inactivation of the NF1 tumor suppressor in gliomagenesis. Cancer Cell 16: $44-54$.

McGuire CS, Sainani KL, Fisher PG. 2009. Both location and age predict survival in ependymoma: A SEER study. Pediatr Blood Cancer 52: 65-69.

Molofsky AV, He S, Bydon M, Morrison SI, Pardal R. 2005. Bmi1 promotes neural stem cell self-renewal and neural development but not mouse growth and survival by repressing the p16Ink4a and p19Arf senescence pathways. Genes Dev 19: 1432-1437.

Nakamura Y, Sakakibara S, Miyata T, Ogawa M, Shimazaki T, Weiss S, Kageyama R, Okano H. 2000. The bHLH gene hes1 as a repressor of the neuronal commitment of CNS stem cells. J Neurosci 20: 283-293.

Okano H, Temple S. 2009. Cell types to order: Temporal specification of CNS stem cells. Curr Opin Neurobiol 19: 112-119.

Ostenfeld T, Joly E, Tai YT, Peters A, Caldwell M, Jauniaux E, Svendsen CN. 2002. Regional specification of rodent and human neurospheres. Brain Res Dev Brain Res 134: 43-55.

Paugh BS, Qu C, Jones C, Liu Z, Adamowicz-Brice M, Zhang J, Bax DA, Coyle B, Barrow J, Hargrave D, et al. 2010. Integrated molecular genetic profiling of pediatric high-grade gliomas reveals key differences with the adult disease. J Clin Oncol 28: 3061-3068.

Reynolds BA, Tetzlaff W, Weiss S. 1992. A multipotent EGFresponsive striatal embryonic progenitor cell produces neurons and astrocytes. J Neurosci 12: 4565-4574.

Santa-Olalla J, Baizabal JM, Fregoso M, del Carmen Cardenas M, Covarrubias L. 2003. The in vivo positional identity gene expression code is not preserved in neural stem cells grown in culture. Eur J Neurosci 18: 1073-1084.

Sharma MK, Mansur DB, Reifenberger G, Perry A, Leonard JR, Aldape KD, Albin MG, Emnett RJ, Loeser S, Watson MA, et al. 2007. Distinct genetic signatures among pilocytic astrocytomas relate to their brain region origin. Cancer Res 67: 890-900.

Shoemaker LD, Orozco NM, Geschwind DH, Whitelegge JP, Faull KF, Kornblum HI. 2010. Identification of differentially expressed proteins in murine embryonic and postnatal cortical neural progenitors. PLOS ONE 5: e9121. doi: 10.1371/ journal.pone.0009121.

Sinor AD, Lillien L. 2004. Akt-1 expression level regulates CNS precursors. J Neurosci 24: 8531-8541.

Taylor MD, Poppleton H, Fuller C, Su X, Liu Y, Jensen P, Magdaleno S, Dalton J, Calabrese C, Board J, et al. 2005. Radial glia cells are candidate stem cells of ependymoma. Cancer Cell 8: 323-335.

Warrington NM, Woerner BM, Daginakatte GC, Dasgupta B, Perry A, Gutmann DH, Rubin JB. 2007. Spatiotemporal 
differences in CXCL12 expression and cyclic AMP underlie the unique pattern of optic glioma growth in neurofibromatosis type 1. Cancer Res 67: 8588-8595.

Weiss S, Dunne C, Hewson J, Wohl C, Wheatley M, Peterson AC, Reynolds BA. 1996. Multipotent CNS stem cells are present in the adult mammalian spinal cord and ventricular neuroaxis. J Neurosci 16: 7599-7609.

Wu Y, Peng H, Cui M, Whitney NP, Huang Y, Zheng JC. 2009. CXCL12 increases human neural progenitor cell proliferation through Akt-1/FOXO3a signaling pathway. I Neurochem 109: 1157-1167.

Yang H, Mujtaba T, Venkatraman G, Wu YY, Rao MS, Luskin MB. 2000. Region-specific differentiation of neural tubederived neuronal restricted progenitor cells after heterotopic transplantation. Proc Natl Acad Sci 97: 13366-13371.

Yeh TH, Lee DY, Gianino SM, Gutmann DH. 2009. Microarray analyses reveal regional astrocyte heterogeneity with implications for neurofibromatosis type 1 (NF1)-regulated glial proliferation. Glia 57: 1239-1249.

Zarghooni M, Bartels U, Lee E, Buczkowicz P, Morrison A, Huang A, Bouffet E, Hawkins C. 2010. Whole-genome profiling of pediatric diffuse intrinsic pontine gliomas highlights platelet-derived growth factor receptor $\alpha$ and poly (ADPribose) polymerase as potential therapeutic targets. I Clin Oncol 28: 1337-1344.

Zhu Y, Harada T, Liu L, Lush ME, Guignard F, Harada C, Burns DK, Bajenaru ML, Gutmann DH, Parada LF. 2005. Inactivation of NF1 in CNS causes increased glial progenitor proliferation and optic glioma formation. Development 132: 5577-5588. 


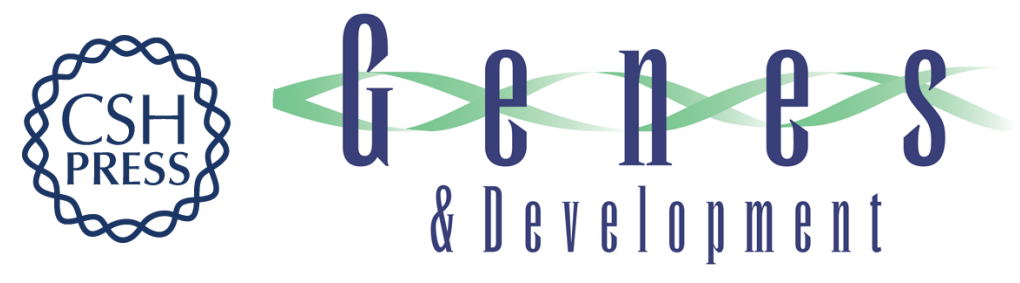

\section{Evidence for and against regional differences in neural stem and progenitor cells of the CNS}

Oren J. Becher and Eric C. Holland

Genes Dev. 2010, 24:

Access the most recent version at doi:10.1101/gad.1988010

\section{Related Content Neurofibromatosis-1 regulates neuroglial progenitor proliferation and glial differentiation in a brain region-specific manner \\ Da Yong Lee, Tu-Hsueh Yeh, Ryan J. Emnett, et al. \\ Genes Dev. October , 2010 24: 2317-2329}

References This article cites 44 articles, 20 of which can be accessed free at:

http://genesdev.cshlp.org/content/24/20/2233.full.html\#ref-list-1

Articles cited in:

http://genesdev.cshlp.org/content/24/20/2233.full.html\#related-urls

\section{License}

Email Alerting

Service

Receive free email alerts when new articles cite this article - sign up in the box at the top right corner of the article or click here.

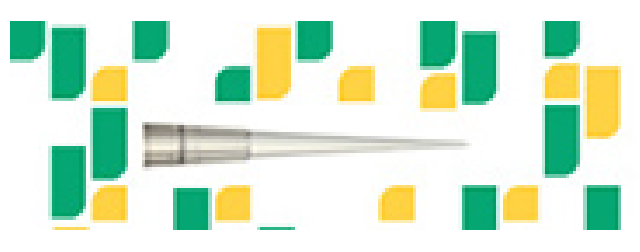

Focused on your science. 